\title{
Penerapan Metode Debat dan Model Artikulasi untuk melihat perbandingan kemampuan Berbicara Siswa kelas XI SMK Negeri Palopo
}

\author{
${ }^{1}$ Besse Herdiana, ${ }^{1}$ Azika Anggraini
}

\begin{abstract}
This research is an experimental research that aims to compare differences in students' speaking abilities using the debate method and articulation models. This study was designed with a post-test only control group desaign. This research was conducted at SMK Negeri 1 Palopo, with a population of 143 students consisting of four classes. Sampling using purposive sample technique so that the chosen ones are accounting class 1 and accounting class 2. The data obtained is data that explains the comparison of speaking skills between those who use the debate method and those who use the articulation model of students of SMK Negeri 1 Palopo, in this study, the data collected will be analyzed by using descriptive statistical techniques and parametric infrential statistics of the type of independent sample T test that is processed with a computer program Statistics Product Service Solution (SPSS). The results showed that the results of the debating method class completeness category contained 29 students who scored $>75$ with a percentage of completeness ( $94 \%)$, and only 2 students who scored $\leq 75$ with a percentage of completeness (6\%). Likewise with the class using the articulation model there were 29 students who scored $>75$ with a percentage of completeness (94\%), and only 2 students who scored $\leq 75$ with a percentage of completeness $(6 \%)$. This proves that there is no significant difference between the speaking ability of class XI students of SMK Negeri 1 Palopo using the debate method and the articulation model Keywords: Articulation; Speaking; Debate
\end{abstract}

\footnotetext{
Abstrak

Penelitian ini adalah penelitian eksprimen yang bertujuan untuk membandingkan ada tidaknya perbedaan kemampuan berbicara siswa dengan menggunakan metode debat dan model artikulasi. Penelitian ini didesain dengan posttest only control group desaign. Penelitian ini dilaksanakan di SMK Negeri 1 Palopo, dengan jumlah populasi 143 siswa yang terdiri atas empat kelas. Penarikan sampel menggunakan teknik sampel bertujuan sehingga yang terpilih adalah kelas akuntansi 1 dan kelas akuntansi 2. Data yang diperoleh adalah data yang menjelaskan perbandingan kemampuan berbicara antara yang menggunakan metode debat dan yang menggunakan model artikulasi siswa SMK Negeri 1 Palopo, dalam penelitian ini, data yang terkumpul akan dianalis dengan menggunakan teknik statistic deskriptif dan statistic infrensial parametik jenis independent sample T test yang diolah dengan program komputer sistem Statistika Product Service Solution (SPSS). Hasil penelitian menunjukkan bahwa Hasil dari kategori ketuntasan kelas metode debat terdapat 29 orang siswa yang mendapat nilai $>75$ dengan persentase ketuntasan (94\%), dan hanya 2 orang siswa yang mendapatkan nilai $\leq 75$ dengan persentase ketuntasan (6\%). Begitupun dengan kelas yang menggunakan model artikulasi terdapat 29 orang siswa yang mendapat nilai > 75 dengan persentase ketuntasan (94\%), dan hanya 2 orang siswa yang mendapatkan nilai $\leq 75$ dengan persentase ketuntasan (6\%). Hal tersebut membuktikan bahwa tidak ada perbedaan yang signifikan antara kemampuan berbicara siswa kelas XI SMK Negeri 1 Palopo menggunakan metode debat dan model artikulasi

Kata Kunci: Artikulasi; Berbicara; Debat
}

${ }^{1}$ Universitas Cokroaminoto Palopo, email: besseherdiana@uncp.ac.id 


\section{PENDAHULUAN}

Berbicara adalah proses komunikasi, gagasan ini dibentuk oleh Tarigan kemudian dikembangkan oleh Abidin. Dalam bukunya pengantar retorika Abidin (2013: 95) memberikan penjelasan bahwa berbicara bukan sekadar pengucapan bunyi-bunyi atau kata-kata, yaitu alat untuk mengkomunikasikan gagasan-gagasan yang disusun serta dikembangkan sesuai dengan kebutuhan pendengar dan penyimak.

Pembalajaran bahasa khususnya pembelajaran berbicara pada tingkat SMA pada dasarnya adalah aktivitas komunikasi dalam bentuk lisan, orientasinya adalah melatih kemampuan siswa dalam hal mengolah kata kemudian memproduksinya dalam bentuk tuturan atau lebih dikenal dengan istilah retorika. Kemampuan retorikan ini bisa digunakan untuk menyatakan gagasan/ asumsi, menyampaikan informasi, kritikan, dan lain hal yang berhubungan dengan komunikasi lisan.

Mengutip gagasan dari Tarigan (2008:2) bahwa tujuan pembelajaran berbicara di sekolah adalah membina siswa, agar mereka memiliki kemampuan berbicara serta retorika yang baik. Siswa diharapkan mampu menyampaikan informasi atau pendapat, menjelaskan ataupun menggambarkan sesuatu hal, kejadian, mengungkapkan pikiran, perasaan serta ide-idenya dalam bahasa lisan. Keterampilan berbicara dapat diukur dengan berbagai metode yang dilaksanakan di kelas.

Berbagai macam usaha yang dilakukan oleh peneliti dan guru untuk melihat hasil kemampuan berbicara siswa salah satunya dengan menggunakan media, model ataupun strategi tertentu agar hasil dari proses pembelajaran dapat terukur secara maksimal. Tujuan pembelajaran akan tercapai tentunya tidak hanya mengandalkan model ataupun strategi yang baru, bagian lain yang menjadi pendukung adalah terciptanya suasana kelas yang kondusif antara pihak pembelajar dalam hal ini siswa dan guru (pendidik).

Pada pelaksanaanya saat ini banyak pendekatan, strategi, ataupun metode yang dilakukan dalam mengajarkan bahasa Indonesia khususnya pada pembelajaran keterampilan berbicara. Terlebih lagi pendekatan, strategi, maupun metode yang sifatnya dapat meningkatkan motivasi, minat siswa dalam pembelajaran. Peneliti akan menggunakan metode debat dengan model artikulasi dalam pembelajaran berbicara. Metode debat dipilih peneliti karena metode ini merupakan metode yang memotivasi siswa untuk terampil berbicara dengan jalan berpikir kritis dalam menanggapi sebuah permasalahan. Sedangkan model artikulasi adalah model pembelajaran dua arah. Dalam hal ini model artikulasi membawa siswa untuk terampil berbicara juga terampil menyimak.

Metode debat merupakan salah satu metode pembelajaran yang sangat penting untuk meningkatkan kemampuan akademik siswa, materi ajar dipilih dan disusun menjadi paket pro, kontra dan netral. Metode debat dapat mengasah kemampuan berbicara siswa karena metode ini menuntut siswa untuk aktif berbicara. Siswa dibagi kedalam kelompok pro, 
kelompok kontra dan kelompok netral, secara aktif siswa akan mengeluarkan argumen, pendapat, pikiran, serta gambarannya tentang mosi yang diberikan. Debat terlukis dengan jelas dalam pembicaraan-pembicaraan atau pidato-pidato yang pro dan kontra.

Berbeda dengan metode debat, model artikulsi adalah model yang prosesnya seperti pesan berantai. Model pembelajaran artikulasi akan membantu siswa untuk memahami materi dengan baik dan melatih siswa untuk mengungkapkan ide-ide mereka secara kreatif dan ilmiah, serta melatih siswa untuk konsentrasi pada materi yang diajarkan. Pembelajaran seperti ini tentu akan membuat siswa terbiasa untuk bertanya kepada pasangan belajar yang mempunyai kemampuan lebih tentang materi pelajaran dan telah mempunyai tempat untuk sharing tentang materi pelajaran yang tidak dimengerti.

Penggunaan metode debat dan model artikulasi pada penelitian ini untuk membandingkan hasil kemampuan berbicara siswa, sehingga yang menjadi pokok permasalahan adalah apakah ada perbedaan antara kemampuan berbicara siswa menggunakan metode debat dan model artikulasi siswa kelas XI SMK 1 Palopo.

\section{METODE PENELITIAN}

Penelitian ini adalah penelitian eksprimen yang didesain dengan posttest only control group desaign. Penelitian ini dilaksanakan di SMK Negeri 1 Palopo, dengan jumlah populasi 143 siswa yang terdiri atas empat kelas. Penarikan sampel menggunakan teknik sampel bertujuan sehingga yang terpilih adalah kelas akuntansi 1 dan kelas akuntansi 2. Data yang diperoleh adalah data yang menjelaskan perbandingan kemampuan berbicara antara yang menggunakan metode debat dan yang menggunakan model artikulasi siswa SMK Negeri 1 Palopo, dalam penelitian ini, data yang terkumpul akan dianalis dengan menggunakan teknik statistic deskriptif dan statistic infrensial parametik jenis independent sample $T$ test yang diolah dengan program komputer sistem Statistika Product Service Solution (SPSS).

\section{HASIL DAN PEMBAHASAN}

\subsection{Data Hasil Penelitian Penggunaan Metode Debat}

Data ini menjelaskan nilai hasil posttest siswa kelas XI SMK Negeri 1 Palopo yang mengikuti pembelajaran berbicara dengan metode debat. Berdasarkan hasil analisis data yang diolah dengan program SPSS versi 20 dapat diketahui hasil belajar siswa kelas XI SMK Negeri 1 Palopo yang mengikuti pembelajaran berbicara dengan metode debat seperti yang dirangkum dalam tabel 1 berikut ini.

Tabel 1. Rangkuman Nilai Statistik

Deskriptif Hasil Kemampuan

Berbicara Siswa Menggunakan Metode Debat

\begin{tabular}{llc}
\hline No. & Statistik Deskriptif & Nilai Statistik \\
\hline 1. & Ukuran Sampel & 31 \\
2 & Nilai Rata-rata & 82,7 \\
3. & Standar Deviasi & 6,08 \\
4 & Nilai Terendah & 72 \\
5. & Nilai Tertinggi & 93 \\
\hline
\end{tabular}

Sumber: Data primer setelah diolah (2019)

Tabel 1, menunjukkan bahwa hasil posttest dari 31 siswa, nilai ratarata yang diperoleh siswa adalah 82,7, standar deviasi 6,08, nilai terendah 72, dan nilai tertinggi 93.untuk 
penjabarannya dapat dilihat pada tabel berikut:

Tabel 2. Distribusi Frekuensi dan Persentase Posttest Skor Siswa Menggunakan Metode Debat

\begin{tabular}{cccc}
\hline No & Skor mentah & Frekuensi & Persentase (\%) \\
\hline 1 & 72 & 1 & $3 \%$ \\
2 & 74 & 1 & $3 \%$ \\
3 & 76 & 3 & $10 \%$ \\
4 & 78 & 5 & $16 \%$ \\
5 & 79 & 2 & $7 \%$ \\
6 & 80 & 3 & $10 \%$ \\
7 & 81 & 2 & $7 \%$ \\
8 & 82 & 1 & $3 \%$ \\
9 & 83 & 1 & $3 \%$ \\
10 & 84 & 2 & $7 \%$ \\
11 & 88 & 2 & $6 \%$ \\
12 & 90 & 2 & $6 \%$ \\
13 & 91 & 5 & $16 \%$ \\
14 & 93 & 1 & $3 \%$ \\
\hline \multicolumn{5}{c}{} & Total & 31 & $100 \%$ \\
\hline
\end{tabular}

Sumber: Data primer sebelum diolah (2019)

Berdasarkan data pada tabel di atas hasil posttest pada kelas eksperimen I diperoleh gambaran, yaitu skor tertinggi 93 diperoleh 1 orang siswa (3\%), yang mendapat skor 91 diperoleh 5 orang siswa $(16 \%)$, skor 90 diperoleh 2 orang siswa $(6 \%)$, skor 88 diperoleh 2 orang siswa $(6 \%)$, skor 84 diperoleh 2 orang siswa $(7 \%)$, skor 83 diperoleh 1 orang siswa (3\%), skor 82 diperoleh 1 orang siswa $(3 \%)$, skor 81 diperoleh 2 orang siswa $(7 \%)$, skor 80 diperoleh 3 orang siswa $(10 \%)$, skor79 diperoleh 2 orang siswa $((7 \%)$, skor 78 diperoleh 5 orang siswa $(16 \%)$, skor 76 diperoleh 3 orang siswa $(10 \%)$, skor 74 diperoleh 1 orang siswa (3\%) dan yang mendapat skor 72 diperoleh 1 orang siswa (3\%).

Skor hasil belajar siswa kelas XI SMK Negeri 1 Palopo yang mengikuti pembelajaran berbicara dengan metode debat tersebut dikelompokkan ke dalam lima kategori, diperoleh klasifikasi skor seperti yang terangkum dalam tabel 3 berikut ini
Tabel 3. Klasifikasi Skor Hasil Belajar Siswa yang Mengikuti Pembelajaran

Berbicara Menggunakan Metode Debat

\begin{tabular}{cccc}
\hline Nilai & Kategori & Frekuensi & Persentase (\%) \\
\hline $0-54$ & Sangat Rendah & 0 & $0 \%$ \\
$55-64$ & Rendah & 0 & $0 \%$ \\
$65-79$ & Sedang & 12 & $39 \%$ \\
$80-89$ & Tinggi & 11 & $35 \%$ \\
$90-100$ & Sangat Tinggi & 8 & $26 \%$ \\
\hline
\end{tabular}

Sumber: Data primer setelah diolah (2019)

\subsection{Data Hasil Penelitian Analisis Statistik Deskriptif Kemampuan Berbicara Siswa Menggunakan Model Artikulasi}

Data ini menjelaskan nilai hasil posttestsiswa kelas XI SMK Negeri 1 Palopo yang mengikuti pembelajaran berbicara dengan model artikulasi. Berdasarkan hasil analisis data yang diolah dengan program SPSS versi 20 dapat diketahui hasil belajar siswa kelas XI SMK Negeri 1 Palopo yang mengikuti pembelajaran berbicara dengan model artikulasi seperti yang terangkum dalam tabel 8 berikut ini.

Tabel 4. Rangkuman Nilai Statistik

Deskriptif Hasil Kemampuan Berbicara Siswa Menggunakan Model Artikulasi

\begin{tabular}{llc}
\hline No. & Statistik Deskriptif & Nilai Statistik \\
\hline 1. & Ukuran Sampel & 31 \\
2. & Nilai Rata-rata & 82,8 \\
3. & Standar Deviasi & 5,57 \\
4. & Nilai Terendah & 73 \\
5. & Nilai Tertinggi & 93 \\
\hline
\end{tabular}

Sumber: Data primer setelah diolah (2019)

Tabel 4, menunjukkan bahwa posttest dari 31 siswa, nilai rata-rata yang diperoleh siswa adalah 82,8, standar deviasi 5,57, nilai terendah 73 dan nilai tertinggi 93. 
Tabel 5. Distribusi Frekuensi dan Persentase Posttest Skor Siswa Menggunakan Model Artikulasi

\begin{tabular}{cccc}
\hline No & Skor mentah & Frekuensi & Persentase (\%) \\
\hline 1 & 73 & 1 & $3 \%$ \\
2 & 74 & 1 & $3 \%$ \\
3 & 76 & 1 & $3 \%$ \\
4 & 77 & 1 & $3 \%$ \\
5 & 78 & 3 & $10 \%$ \\
6 & 79 & 4 & $11 \%$ \\
7 & 80 & 3 & $10 \%$ \\
8 & 81 & 1 & $3 \%$ \\
9 & 82 & 1 & $3 \%$ \\
10 & 83 & 3 & $10 \%$ \\
11 & 85 & 2 & $9 \%$ \\
12 & 86 & 3 & $10 \%$ \\
13 & 87 & 1 & $3 \%$ \\
14 & 90 & 2 & $6 \%$ \\
15 & 92 & 3 & $10 \%$ \\
16 & 93 & 1 & $3 \%$ \\
\hline \multicolumn{5}{c}{} & Total & 31 & $100 \%$ \\
\hline
\end{tabular}

Sumber: Data primer sebelum diolah (2019)

Data pada tabel diatas menunjukan hasil posttest pada kelas eksperimen II diperoleh gambaran yaitu skor tertinggi 93 diperoleh 1 orang siswa (3\%) yang mendapat skor 92 diperoleh 3 orang siswa $(10 \%)$, skor 90 diperoleh 2 orang siswa $(6 \%)$, skor 87 diperoleh 1 orang siswa (3\%), skor 86 diperoleh 3 orang siswa $(10 \%)$, skor 85 diperoleh 2 orang siswa $(9 \%)$, skor 83 diperoleh 3 orang siswa $(10 \%)$, skor 82 diperoleh 1 orang siswa $(3 \%)$, skor 81 diperoleh 1 orang siswa (3\%), skor 80 diperoleh 3 orang siswa $((10 \%)$, skor 79 diperoleh 4 orang siswa $(11 \%)$, skor 78 diperoleh 3 orang siswa $(10 \%)$, skor 77 diperoleh 1 orang siswa $(3 \%)$, skor 76 diperoleh 1 orang siswa $(3 \%)$, skor 74 diperoleh 1 orang siswa (3\%), dan yang mendapatkan skor 73 diperoleh 1 orang siswa $(3 \%)$.

Skor hasil belajar siswa kelas XI SMK Negeri 1 Palopo yang mengikuti pembelajaran berbicara dengan modelartikulasi tersebut dikelompokkan ke dalam lima kategori, diperoleh klasifikasi skor seperti yang terangkum dalam tabel berikut ini.

Tabel 6. Klasifikasi Skor Hasil Belajar Siswa yang Mengikuti Pembelajaran

Berbicara Menggunakan Model Artikulasi

\begin{tabular}{cccc}
\hline Nilai & Kategori & Frekuensi & Persentase (\%) \\
\hline $0-54$ & Sangat Rendah & 0 & $0 \%$ \\
$55-64$ & Rendah & 0 & $0 \%$ \\
$65-79$ & Sedang & 11 & $36 \%$ \\
$80-89$ & Tinggi & 14 & $45 \%$ \\
$90-100$ & Sangat Tinggi & 6 & $19 \%$ \\
\hline
\end{tabular}

Sumber: Data primer setelah diolah (2019)

Data di atas menunjukkan bahwa tidak ada siswa pada kategori sangat rendah dan rendah, 11 siswa (36\%) berada pada kategori sedang, 14 siswa (45\%) berada pada kategori tinggi, dan 6 siswa (19\%) berada pada kategori sangat tinggi

\subsection{Uji Normalitas}

Berdasarkan hasil analisis data uji normalitas yang diolah dengan program SPSS versi 20untuk mengetahui apakah data yang mengikuti populasi berdistribusi normalantara metode debat dan model artikulsi dapat diketahui dalam tabel 12 berikut ini.

Tabel 7. Uji Normalitas Antara Metode Debat dan Model Artikulasi

\begin{tabular}{lccc}
\hline \multicolumn{4}{l}{ One-Sample Kolmogorov-Smirnov Test } \\
\hline & $\mathbf{N}$ & Kolmogorov-SmirnovZ & Asymp.Sig. (2-tailed) \\
\hline Debate & 31 & .890 & 0,407 \\
Articulation & 31 & .857 & 0.454
\end{tabular}

Sumber: Data primer setelah diolah (2019)

Uji normalitas dalam penelitian ini, dengan menggunakan KolmogorovSmirnov, untuk mengetahui apakah data yang mengikuti populasi berdistribusi normal. Dengan ketentuan bahwa jika nilai $p>\alpha=0,05$, maka data tersebut berasal dari data 
yang berdistribusi normal dan apabila nilai $p<a=0,05$ maka data tersebut tidak berdistribusi normal .Data hasil analisis SPSSversi 20 menunjukkan bahwa hasil uji normalitas memeroleh nilai $p=0,407$ untuk kelas yang mengikuti pembelajaran berbicara dengan menggunakan metode debat dan $p=0,454$ untuk kelas yang mengikuti pembelajaran berbicara dengan menggunakan model artikulasi. Jadi nilai normalitas untuk pembelajaran metode debat $p=0,407>$ $\mathrm{a}=0,05$ maka dapat dikatakan berdistribusi normal. Begitupun dengan nilai normalitas untuk pembelajaran model artikulasi $p=0,454$ $>\mathrm{a}=0,05$ maka dapat dikatakan juga berdistribusi normal. Data skor kemampuan berbicara siswa menggunakan metode debat dan model artikulasi berasal dari populasi yang berdistribusi normal.

\subsection{Uji Homogenitas Variabel}

Uji homogenitas variabel dimaksudkan untuk menguji kedua varian kelompok adalah sama. Jika nilai signifikan $>0,05$ maka distribusi data homogen dalam artian memiliki varian yang sama. Berdasarkan hasil analisis data uji homogenitas variabel yang diolah dengan program SPSS versi 20untuk mengetahui apakah data yang mengikuti populasi berdistribusi data homogenantara metode debat dan model artikulasi dapat diketahui dalam tabel 13 berikut ini

Tabel 33. Uji Homogenitas Antara Metode Debat dan Model Artikulasi

\begin{tabular}{|c|c|c|c|}
\hline \multicolumn{4}{|c|}{ Test of Homogeneity of Variances } \\
\hline & df1 & df2 & Sig \\
\hline Debat & 1 & 60 & 0,413 \\
\hline Artikulasi & 1 & 60 & 0,413 \\
\hline \multicolumn{4}{|c|}{ Test of Homogeneity of Variances } \\
\hline & df1 & df2 & Sig \\
\hline Debat & 1 & 60 & 0,413 \\
\hline Artikulasi & 1 & 60 & 0,413 \\
\hline
\end{tabular}

Sumber: Data primer setelah diolah (2019)
Berdasarkan hasil perhitungan dengan menggunakanprogram SPSS versi 20, diketahui nilai F hitung antara metode debat dan model artikulasi adalah 0,413. Maka dapat dikatakan bahwa nilai signifikan diantara keduanya adalah $0,413>0,05$ sehingga dapat dikatakan bahwa kedua kelompok memiliki varian yang sama atau homogen.

Berdasarkan hasil analisis skor hasil belajar keterlibatan siswa kelas XI SMK Negeri 1 Palopo yang mengikuti pembelajaran berbicara yang diberikan perlakuan dengan metode debat dan yang diberikan perlakuan dengan model artikulasi dapat dikatahui ada tidaknya perbedaan keterlibatan siswa pada kedua metode pembelajaran tersebut. Perbandingan skor hasil belajar siswa diukur dengan menggunakan analisis inferensial parametrik jenis Independent Sampel $T$ Test. Syarat yang harus dipenuhi untuk pengujian hipotesis jenis Independendent Sampel $T$ Test adalah data yang diperoleh berdistribusi normal dan mempunyai hasil yang homogen. Oleh karena itu, terlebih dahulu dilakukan uji normalitas dan uji homogenitias.

Analisis data yang diperoleh dengan menggunakan program SPSS versi 20, diperoleh hasil keputusan berdasarkan statistik inferensial jenis uji $\mathrm{t}$ diketahui $\mathrm{t}$ hitung $(0,109)<\mathrm{t}$ tabel $(0,161)$, maka $\mathrm{H}_{0}$ diterima. Seperti yang dikemukakan oleh Sugiyono (dalam Nita 2017: 91) mengenai pengambilan keputusan uji $t$, bila terjadi penerimaan HO maka dapat disimpulkan tidak terdapat perbedaan signifikan. Dengan demikian, ditemukan bahwa tidak ada perbedaan yang signifikan terhadap kemampuan berbicara siswa 
kelas XI SMK Negeri 1 Palopo menggunakan metode debat dengan yang menggunakan model artikulasi. Metode debat dan model artikulasi memiliki karakteristik tersendiri dan keduanya sama-sama baik digunakan pada kemampuan berbicara siswa karena nilai yang dihasilkan berada pada kategori baik berdasarkan aspek penilaian berbicara.

\section{KESIMPULAN}

Hasil dari kategori ketuntasan kelas metode debat terdapat 29 orang siswa yang mendapat nilai $>75$ dengan persentase ketuntasan (94\%), dan hanya 2 orang siswa yang mendapatkan nilai $\leq 75$ dengan persentase ketuntasan (6\%). Begitupun dengan kelas yang menggunakan model artikulasi terdapat 29 orang siswa yang mendapat nilai > 75 dengan persentase ketuntasan (94\%), dan hanya 2 orang siswa yang mendapatkan nilai $\leq 75$ dengan persentase ketuntasan (6\%). Hal tersebut membuktikan bahwa tidak ada perbedaan yang signifikan antara kemampuan berbicara siswa kelas XI SMK Negeri 1 Palopo menggunakan metode debat dan model artikulasi. Secara analisis deskriptif terdapat persamaan nilai yang diperoleh antara metode debat dan model artikulasi. Namun keduanya memiliki karakteristik masing-masing yang menjadi dasar penilaian pembelajaran berbicara itu sendiri.

\section{DAFTAR PUSTAKA}

Abidini, Y. (2013). Pengantar Retorika. Bandung: Pustaka Setia

Arikunto, S. (2005). Dasar-dasar Evaluasi Pendidikan, Jakarta: Bumi Aksara
Arikunto, S. (2006) .Prosedur Penelitiian Suatu Pendekatan Praktik. Mataram: Rineke Cipta

Djumingin, S. (2010). Penilaian dan Pembelajaran Bahasa dan Sastra Indonesia (Teori dan Penerapannya). Makassar: Badan Penerbit UNM

Nurgiyantoro, B. (1995). Penilaian Pengajaran Bahasa dan Sastra. Yogyakarta: BPEE.

Tarigan, H. (2002). Berbicara sebagai suatu Keterampilan Berbahasa. Bandung: Angkasa Bandung 